\title{
Treatment outcome of Diarrhea with or without Probiotics among Children aged 12-60 months \\ Muhammad Nadeem Yousaf, ${ }^{1}$ Muhammad Awais, ${ }^{2}$ Muhammad Ans, ${ }^{3}$ Adnan Afzal, ${ }^{4}$ Fawad Hussain, ${ }^{5}$ Amjad Hayat, ${ }^{6}$ Muhammad Imran Sarwer
}

\begin{abstract}
Background: High mortality rate around the globe has been reported due to diarrheal disease among all fewer than five years of age. Many studies show their utilization in the treatment of diarrheal disease especially among children of under-five.

Objective: To assess the treatment outcome of diarrhea with and without probiotics among children aged 12-60 months.

Methodology: This comparative cross-sectional study was undertaken from July to December 2017. A pre-designed questionnaire was used to collect the information in terms of antibiotics, rehydrating agents, antipyretic agents, and probiotics. A total of 109 patients were selected randomly and then divided into two groups as "probiotic" having 55 children and "Non-Probiotic", having 54 children. Guardians of patients were contacted telephonically after 48 hours and 72 hours to ask about the time frame of relief from symptoms, diarrheal episodes, and cure from disease. Data were analyzed by using SPSS 20.

Results: Out of 109 patients, 54 patients were in the non-probiotic group and 55 in the probiotic group. The overall age of patients remained $31 \pm 12$ months. Saccharomyces boulardii (56.4\%) and Lactobacillus GG (43.6\%) were probiotics prescribed by pediatric physicians. A significant difference $(\mathrm{p}=0.000)$ was observed in terms of treatment outcome showing early relief $(12 \mathrm{hrs}) 43(78 \%)$ vs $22(41 \%)$ in probiotic vs non-probiotic group and early cure $(<48$ $\mathrm{hrs}$ ) from diarrhea in probiotic group $48(87 \%)$ vs 35 (65\%) as compared to the non-probiotic group. $(\mathrm{p}=0.00)$

Conclusion: The use of probiotics during the treatment of acute diarrhea among children below five years shortens the duration of symptoms and helps the cure as early as one day before the patients' not using probiotics.
\end{abstract}

Key words: Probiotics, Diarrhea, Children, ORS.

Article Citation: Yousaf MN, Awais M, Ans M, Afzal A, Hussain F, Hayat A, Sarwer MI. Treatment outcome of Diarrhea with or without Probiotics among Children aged 2-60 months. JSZMC 2020;10(2):13-17. DOI: https://doi.org/10.47883/jszmc.v11i2.72

\section{Introduction}

Use of oral rehydration salts (ORS) containing zinc and provision of sustained feedstuff is the treatment recommended among young children, suffering from community-based acquired acute diarrhea. ${ }^{1}$ Diarrhea is a Greek word used to elaborate the more liquidity or watery stools which are linked augmented rate of defecation with high fecal weight. World health organization (WHO) described it as three or more episodes of watery stools per day for two or more consecutive days. On the other hand, different types of diarrhea are explained conferring different modes of action. These types include osmotic, secretary, inflammatory and motility associated diarrheas. ${ }^{2}$

A high mortality rate of $15 \%$ around the globe has been reported due to diarrheal disease among all under five years of age causalities, thus making the disease as the second largest reason for demise among pediatrics. ${ }^{3}$ The highest burden of mortality among under-five has been reported in economically deprived regions or in developing countries like South Asia and Sub-Saharan Africa. World Health Organization (WHO) has reported a high mortality rate of 73.1/1000 live births is fourteen times greater than developed countries which show death rate of 5.3/1000 live births. ${ }^{4}$ Pakistan has been ranked at number $26^{\text {th }}$ among all countries for under-five mortality with current rates of 78.8/1000 as proposed in a current report of United Nations International Children's Emergency Fund (UNICEF) with a reduction of 141 deaths in 1990 to 79 in $2016 .{ }^{5}$ Diarrhea has been reported one of the major causes of death among children aged under-five. ${ }^{6}$ Presently

1. Department of Medicine, Jinnah Hospital, Allama Iqbal Medical College, Lahore, Pakistan.

2. Nawaz Sharif Social Security Hospital, Lahore, Pakistan.

3. RHC, Zahir Pir, Rahim Yar Khan, Pakistan.

4. Rai Medical College, Sargodha, Pakistan.

5. Niazi Medical College, Sargodha, Pakistan.

6. Sahara Medical College, Narowal, Pakistan.

7. Quaid-e-Azam Medical college, Bahawalpur, Pakistan

Correspondence: Dr. Muhammad Imran Sarwer, Micro/Molecular Biologist, Quaid-e-Azam Medical College Bahawalpur, Pakistan.

Email:Imransarwar469@gmail.com Received: 15-02-2020 Revised: 29-03-2020 
WHO has recommended ORS to abridge the duration and intensity of episode however upsurging popular probiotics are ignored at some extent.

Probiotics are utilized in various health issues and significance has been found to be in gastrointestinal disorders especially in antibioticassociated diarrheal conditions, acute pancreatic, bowel inflammation, irritable bowel syndrome, upper respiratory tract infections, liver cirrhosis, and helicobacter pylori infection. ${ }^{3}$ Though the precise mode of action for utilization of probiotics is hypothetical yet therefore generally thought to overpower the pathogenic bacteria by promoting the growth of normal flora which further releases various cytokines and biomolecules to vanish the pathogens. ${ }^{6}$ High burden of drug resistance amongst micro-organisms has challenged the medical science to a considerable extent, whereas available antibiotics contain side effects of undesirable nature thus creating uncertainty among clinicians in prescribing a suitable regime. ${ }^{6}$

Food \& Agriculture Organization of United Nations in collaboration with WHO; defined probiotics as "Living microbes which when engulfed in appropriate quantities, bring health benefits to consumers". ${ }^{7}$ For the purpose of maintenance of healthy equilibrium of intestinal biota; microbial remedies are considered as complementary or alternative medicine and has been proved itself as an efficient instrument to handle a variety of gastric problems. Probiotics are considered useful and many health conditions most of which are related to gastrointestinal tract include antibiotic-associated infectious diarrhea, irritable bowel syndrome, bowel inflammation, acute pancreatitis, helicobacter pylori infection, upper respiratory tract infection, and liver cirrhosis. 8,9

Though probiotics are not recommended by WHO even then, many studies show their utilization in the treatment of diarrheal disease especially among children of under-five. ${ }^{1}$ It has been observed that few pediatricians prescribe probiotics for the children of age 12-60 months presenting with diarrhea while others rely on ORS and antibiotics. Considering this observation, the aim of the present study was to compare the treatment outcome of diarrhea with or without probiotics among children of age 12-60 months.

\section{Methodology}

This comparative cross-sectional study was undertaken in outpatients of Pediatrics Medicine, Jinnah Hospital, Lahore, and Niazi Welfare Teaching Hospital, Sargodha from July to December 2018. A total of 120 (60 in each group) patients were initially recruited in present study however on telephonic follow-up 11 patients could not be approached appropriately and 109 patients were included for analysis, in two groups as "probiotic" having 55 children and "Non-Probiotic", having 54 children. A pre-designed questionnaire was used to collect information from the guardians of children aged 1260 months and suffering from acute diarrhea.

After taking the informed verbal consent demographic data was collected, the prescription of selected patients was observed and noted in terms of antibiotics, rehydrating agents, antipyretic agents, and probiotics. Patients were then divided in two groups, one group named "probiotic group" who were prescribed probiotics and others was "NonProbiotic group" who were not prescribed. Then the guardian of each patient was contacted telephonically after 48 hours and 72 hours to ask about the time duration of relief from symptoms, diarrheal episodes, and cure from disease. Ethical approval was sought from the Ethical Committee of the Hospital.

Data was entered and analyzed by using SPSS 20 . Quantitative variables like age were presented in terms of mean \pm standard deviation while qualitative variables like cure and relief of symptoms, were presented as frequency and percentage. Proportions were compared using the chi-square test and $\mathrm{p}$-value $<0.05$ was considered as significant.

\section{Results}

A total of 120 (60 in each group) patients were initially recruited in the present study however, on telephonic follow-up 11 patients could not be approached appropriately. Remaining 109 patients as 54 patients in the non-probiotic group and 55 in the probiotic group were included in the final analysis. The overall mean age of patients was $31 \pm 12$ months. The demographic characteristics of patients are shown in Table -I.

Ciprofloxacin belonging to the quinolone group was the most frequently prescribed $(65.2 \%)$ antibiotic while Metronidazole was prescribed in $(87.2 \%)$ as an anti-parasitic agent. Saccharomyces boulardii (56.4\%) and Lactobacillus GG (43.6\%) were 
Table-I: Group-wise Demographic Characteristics of Patients

\begin{tabular}{|c|c|c|c|c|}
\hline \multirow[b]{2}{*}{ Characteristics } & \multirow[b]{2}{*}{ Category } & \multicolumn{2}{|c|}{ Group } & \multirow[b]{2}{*}{$\begin{array}{c}\text { Total } \\
(\mathbf{N}=109) \\
\text { n(\%) }\end{array}$} \\
\hline & & $\begin{array}{c}\text { Probiotic } \\
(\mathbf{N}=55) \\
\mathbf{n}(\%)\end{array}$ & $\begin{array}{c}\text { Non Probiotic } \\
(\mathbf{N}=54) \\
\mathbf{n}(\%)\end{array}$ & \\
\hline \multirow{2}{*}{ Gender } & Male & $28(50.9)$ & $30(55.6)$ & $58(53.2)$ \\
\hline & Female & $27(49.1)$ & $24(44.4)$ & $51(46.8)$ \\
\hline Age & Mean \pm SD & $30.80 \pm 12.06$ & $31.21 \pm 12.28$ & $31.00 \pm 12.12$ \\
\hline $\begin{array}{l}\text { History of } \\
\text { Prior } \\
\text { Treatment }\end{array}$ & Present & $21(38.2)$ & $13(24.1)$ & $34(31.2)$ \\
\hline
\end{tabular}

Table-II: Group-wise Demographic Characteristics of Patients

\begin{tabular}{|c|c|c|c|c|}
\hline \multirow[b]{2}{*}{ Treatment/Outcome } & \multirow[b]{2}{*}{ Type } & \multicolumn{2}{|c|}{ Group } & \multirow[b]{2}{*}{$\begin{array}{c}\text { Total } \\
(\mathbf{N}=109) \\
\mathbf{n}(\%)\end{array}$} \\
\hline & & $\begin{array}{c}\text { Probiotic } \\
(\mathrm{N}=55) \\
\mathbf{n}(\%) \\
\end{array}$ & $\begin{array}{c}\text { Non Probiotic } \\
(\mathbf{N}=54) \\
n(\%)\end{array}$ & \\
\hline \multirow{3}{*}{$\begin{array}{l}\text { Oral Antibiotic } \\
\text { (Single) }\end{array}$} & Ciprofloxacin & $35(63.7)$ & $36(66.7)$ & $71(65.2)$ \\
\hline & Cephalosporin & $12(21.8)$ & $9(16.7)$ & $21(19.3)$ \\
\hline & Trimethoprim & $2(3.6)$ & $1(1.8)$ & $3(2.7)$ \\
\hline $\begin{array}{l}\text { Oral Antibiotic } \\
\text { (Double) }\end{array}$ & $\begin{array}{c}\text { Ciprofloxacin }+ \\
\text { Cephalosporin }\end{array}$ & $6(10.9)$ & $8(14.8)$ & $14(12.8)$ \\
\hline \multirow{2}{*}{$\begin{array}{l}\text { Oral Anti-parasitic } \\
\text { Agent }\end{array}$} & Metronidazole & $47(85.5)$ & $48(88.9)$ & $95(87.2)$ \\
\hline & Furazolidone & $8(14.5)$ & $6(11.1)$ & $14(12.8)$ \\
\hline \multirow{2}{*}{$\begin{array}{l}\text { Type of Probiotic } \\
\text { Prescribed }\end{array}$} & S. boulardii* & $31(56.4)$ & - & $31(28.5)$ \\
\hline & $\begin{array}{c}\text { Lactobacillus } \\
\text { GG }\end{array}$ & $24(43.6)$ & - & $24(22.0)$ \\
\hline \multicolumn{4}{|c|}{ Measure of Treatment Outcome } & p-value \\
\hline \multirow{3}{*}{$\begin{array}{l}\text { Relief from } \\
\text { Symptoms }\end{array}$} & $\begin{array}{c}\text { Within } 12 \\
\text { Hours }\end{array}$ & $43(78.2)$ & $22(40.8)$ & \multirow{3}{*}{0.0001} \\
\hline & $\begin{array}{l}\text { Within } 24 \\
\text { Hours }\end{array}$ & $11(21.8)$ & $25(46.3)$ & \\
\hline & $>24$ Hours & - & $7(12.9)$ & \\
\hline \multirow{2}{*}{ Cure from Diarrhea } & 24-47 Hours & $48(87.3)$ & $35(64.8)$ & \multirow{2}{*}{0.0061} \\
\hline & 48-72 Hours & $7(12.7)$ & $19(35.2)$ & \\
\hline
\end{tabular}

probiotics prescribed by pediatric physicians. A significant difference was observed in terms of treatment outcome showing early relief and early cure from diarrhea in the probiotic group as compared to the non-probiotic group. A comparison of prescribed treatment and its outcome among both groups is shown in table II. All the prescriptions included the use of ORS for rehydration or to avoid dehydration among patients.

\section{Discussion}

Saccharomyces boulardii (56.4\%) and Lactobacillus GG $(43.6 \%)$ were the probiotics of choice in present study. Saccharomyces boulardii is a yeast, which is non-pathogenic and considered as an antiinflammatory and release enzymes, antimicrobial agents, contains anti-toxic and good metabolic activities, which help to increase the trophic effect on the metabolic function of the mucosa of the gastrointestinal tract. ${ }^{8}$ Few other studies have also demonstrated the safety and therapeutic effect of Saccharomyces boulardii in acute diarrheal infections. ${ }^{9,10}$ Benefits of Lactobacillus GG are also appropriately studied probiotic and the bacterium 
has been reported to be effective in treating many gut problems among children including a reduction in gut pain, Clostridium difficile associated diarrhea, antibiotic-associated diarrhea, hospital-acquired gut infections and reduction in duration of infectiousness. ${ }^{11,12}$

A significant difference ( $p$-value $<0.05$ ) in terms of relief from symptoms and cure from diarrhea has been observed among probiotic and nonprobiotic groups in the present study. The probiotic group showed faster relief and early cure from diarrhea while the non-probiotic group remained slow. Results of the present study are comparable with the previous study, which reported that probiotics help to shorten the duration of diarrheal illness by at least one day on average and further elaborated that most of the people using probiotics have no more gut problem after 3 days. ${ }^{13}$ However, differences among the type of organism used, quality of products and ability of individuals to digest the probiotics may vary and can affect the outcome significantly. ${ }^{13}$

The significance increase in the use of probiotics has pressurized the related industry to show their intense concern to get benefits from healthenhancing micro-biota at a global level. Trends have shown their effects in Pakistan also as a recent study to find the parental experience about using probiotics concluded that there is limited use of probiotics in treating the children having gastrointestinal problems. A limited class having knowledge about probiotics and bearing considerable resources is able to use probiotics. Further a varied number of people do not know about the live organisms being used in probiotics. $^{14}$

Lack of knowledge and inadequate resources of people is the main issue along with a high proportion of illiteracy, which are major factors in decreasing the access of the general public to important health products. A report published in 2014 evidenced that the average expense of people on probiotics in Pakistan is near 0US\$ per person. ${ }^{15}$ Contrary to these observations revealed extensive use of probiotics in few situations and people mostly consider probiotics as medicine as these are only prescribed by physicians. Similarly, extensive uses of probiotics in cereals, milk powder, dairy products, yogurt, and frozen desserts have also been reported. ${ }^{16}$

Contrary to the results reported in the present study there are many factors for using or not using probiotics among children without letting the knowledge of the physician. A study in Pakistan revealed that probiotic users' perception is maintaining gastric health upright thus bears knowledge about benefits of probiotics in supporting the immune system, decreasing allergic skin and preventing vagina infections. ${ }^{14}$ Whilst, a study reported that around $59 \%$ consumers of probiotics do not let their physician know due to considering it unimportant. The distress of side effects has been found to be a negative confounder among a few people and consider it as a pill. Whereas many probiotics foods including fermented milk, milk products, kefir, and yogurt are not considered as probiotics among general people and consume these products as functional food products. ${ }^{17}$ A metaanalysis reported that the treatment of diarrhea using probiotics appeared to avert few variations associated with antibiotics especially penicillin and advised long term consumption of probiotics, which ultimately influence the development of batter micro-biota among children hence enhance provide immunity from gut infections. ${ }^{18}$

\section{Conclusion}

This study concluded that the use of probiotics during the treatment of acute diarrhea among children below five years shortens the time of symptoms and helps the cure as early as one day before the patients' not consuming probiotics.

Authors Contribution: MNY: Conception of work and Design of Work. MA: Drafting and Revising. MA \& AA: Acquisition \& analysis. FA \& AH: Analysis of data and drafting. MIS: Acquisition \& analysis.

All the authors gave final approval for publication and agreed to be accountable for all aspect of work.

\section{Conflict of Interest: None \\ Sources of Funding: Self}

\section{References}

1. Applegate, J. A., Walker, C. L. F., Ambikapathi, R., Black, R. E. Systematic review of probiotics for the treatment of community-acquired acute diarrhea in children. BMC Public Health 2013; 13(3): S16.

2. De Vrese, M., Marteau, P. R. Probiotics and prebiotics: effects on diarrhea. JNutr 2007; 137(3): 803-11.

3. Alebel, A., Tesema, C., Temesgen, B., Gebrie, A., Petrucka, P., \& Kibret, G. D. Prevalence and determinants of diarrhea among under-five children in Ethiopia: A systematic review and meta-analysis. PloS one, 2018; 13(6): $\mathrm{e} 0199684$ 
4. World Health Organization: Global Health Observatory (GHO) data under-five mortality. [Updated 2018, cited 2018] Available from URL: [http://www.who.int/gho/ child health/mortality/mortality under five text.

5. Trends in Under-5 mortality rates. UNICEF, 2016.[Updated 2016, cited 2018] Available from URL: [https://data.unicef.org/country/pak/].

6. Liu, L., Johnson, H. L., Cousens, S., Perin, J., Scott, S., Lawn, J. E., Mathers, C. Child Health Epidemiology Reference Group of WHO and UNICEF Global, regional, and national causes of child mortality: an updated systematic analysis for 2010 with time trends since 2000. Lancet 2012;379(9832): 2151-61.

7. Food and Agriculture Organization of the United Nations and World Health Organization. Guidelines for the Evaluation of Probiotics in Food. Rome: Food and Agriculture Organization; 2002. Available at: ftp://ftp.fao.org/es/esn/food/wgreport2.pdf.

8. Kelesidis, T., Pothoulakis, C. Efficacy and safety of the probiotic Saccharomyces boulardii for the prevention and therapy of gastrointestinal disorders. Therap Adv Gastroenterol 2012; 5(2): 111-25.

9. Das, S., Gupta, P. K., Das, R. R. Efficacy and safety of Saccharomyces boulardii in acute rotavirus diarrhea: double blind randomized controlled trial from a developing country. J Trop Pediatr 2016; 62(6): 464-70.

10. Erdoğan, Ö., Tanyeri, B., Torun, E., Gönüllü, E., Arslan, H., Erenberk, U., Öktem, F. The comparition of the efficacy of two different probiotics in rotavirus gastroenteritis in children. J Trop Med 2012:

11. Horvath, A., Dziechciarz, P., \& Szajewska, H. Meta-analysis: Lactobacillus rhamnosus GG for abdominal pain-related functional gastrointestinal disorders in childhood. Aliment Pharmacol Ther 2011; 33(12): 1302-10.
12. Szajewska, H., Wanke, M., \& Patro, B. Meta-analysis: the effects of Lactobacillus rhamnosus GG supplementation for the prevention of healthcare-associated diarrhoea in children. Aliment Pharmacol Ther 2011;34(9): 1079-87.

13. PubMed Health. Infectious diarrhea: Can probiotics help against diarrhea? [Updated, 2016; Cited 2018] Available from URL: [https://www.ncbi.nlm.nih.gov/ pubmedhealth/PMH0088733/].

14. Munir MK, Khaliq S, Rehman S, Azhar H, Riaz I, Baig AA. Parental experience and use of probiotics among children aged twelve months and above. Asian Journal of Medicine and Biomedicine. 2019 Apr 29; 3(1): 9-14.

15. Hui Wan S. Global and regional trends of the probiotics and omega fatty acids markete. USChina Health Product Association. Updated June, 2015. Accessed March 2018. Available from website : [http://uschinahpa.org/ wpcontent/uploads/2015/07/EMI-US-ChinaHPAProbiotic-and-Omega-2015-Final.pdf]

16. Afzaal M, Zahoor T, Arshad MU, Maan AA, Shahbaz M, Zafarullah M, Abid T. Probiotics: Health Claims, Potential and Realities. Pak J Food Sci 2013; 23(3): 139-43.

17. Rijkers GT, Bimmel D, Grevers D, den Haan N, Hristova Y. Consumer perception of beneficial effects of probiotics for human health. Benef Microbes 2013; 4(1): 117-21.

18. Korpela, K., Salonen, A., Virta, L. J., Kumpu, M., Kekkonen, R. A., De Vos, W. M. Lactobacillus rhamnosus GG intake modifies preschool children's intestinal microbiota, alleviates penicillin-associated changes, and reduces antibiotic use. PloS one 2016; 11(4): e0154012. 